\title{
Role of Glutamatergic System in Obsessive-Compulsive Disorder with Possible Therapeutic Implications
}

\author{
Authors \\ Přemysl Vlček1, 2, Jakub Polák1, Martin Brunovskýn', 2, Jiří Horáček ${ }^{1,2}$
}

\section{Affiliations}

1 National Institute of Mental Health, Topolová 748, 250 67 Klecany, Czech Republic

2 Third Faculty of Medicine, Charles University, Ruská 87, 10000 Prague 10, Czech Republic

\section{Key words}

amygdala-hippocampus complex, checking obsession, CSTC circuitry, glutamatergic agent, $\mathrm{OCD}$, temporal lobe

$\begin{array}{ll}\text { received } & 26.06 .2017 \\ \text { revised } & 07.08 .2017 \\ \text { accepted } & 11.08 .2017\end{array}$

\section{Bibliography}

DOI https://doi.org/10.1055/s-0043-118665

Published online: 26.9.2017

Pharmacopsychiatry 2018; 51: 229-242

(c) Georg Thieme Verlag KG Stuttgart · New York

ISSN 0176-3679

\author{
Correspondence \\ PremysI Vlcek \\ National Institute of Mental Health \\ Applied Brain Electroencephalography \\ Topolova 748 \\ 25067, Klecany \\ Czech Republic \\ premysl.vlcek@nudz.cz
}

\begin{abstract}
Obsessive-compulsive disorder (OCD) is a chronic psychiatric illness and 1 of the most common anxiety disorders with the prevalence of $3 \%$. Although its pathogenesis remains unclear, the traditional model focused on alternations in the serotonin system. Selective serotonin reuptake inhibitors provide the most effective treatment; however, as much as $40-60 \%$ of patients do not respond to antidepressants therapy. Thus, attention has shifted towards other neurotransmitter systems and related neuroanatomical structures. Recently, there is extensive evidence showing a key role of glutamate pathways abnormalities within the cortico-striatal-thalamo-cortical circuitry and temporal lobes in OCD pathogenesis. In this review, we link together the existent neuroanatomical, neurophysiological, and neuropsychological evidence to argue for potential benefits of adjuvant treatment with glutamatergic agents, especially memantine. By a targeted de-excitation effect on the glutamatergic system in the temporal lobes and connected brain regions, memantine might further alleviate OCD symptoms. This effect should be even more pronounced in certain subtypes of patients with specific cognitive deficits and maladaptive compensatory memory processes (e.g., checkers).
\end{abstract}

\section{Introduction}

Obsessive-compulsive disorder (OCD) is a common and debilitating psychiatric illness with the high prevalence of $1-3 \%$, which makes it the fourth most common mental disorder [1,2]. Apart from the public health impact, it also presents a considerable economic burden; while $€ 2.72$ billion were estimated to be spent in 2010 for the treatment and management of OCD in Europe [3], data from the United States show striking $\$ 14.6$ billion spent in 1990 [4]. The most effective first-line treatment (up to $70 \%$ of cases) involves cognitive-behavioral therapy (CBT) in combination with pharmacological treatment [5]. Especially serotonergic agents including selective serotonin reuptake inhibitors (SSRIs) and clomipramine have provided the mainstay of OCD medication management for decades and are still considered the primary pharmacological treatment avenue [6]. Despite the efficacy of serotoner- gic compounds in the treatment of OCD, treatment-resistant symptoms remaining in $40-60 \%$ of patients present a clinical problem [7]. In this case, a medication switch for another SSRI or augmentation with atypical antipsychotics (e.g., aripiprazole) is necessary [8] and may be beneficial for another $40 \%$ of patients nonresponsive to the first selected drug $[9,10]$.

\section{Neuroanatomical and Neurophysiological Structure of OCD}

\section{CSTC circuit and glutamatergic system}

So far, specific causes of OCD have remained unclear. It was historically considered to be exclusively of psychogenic origins; howev- 
er, current neuropsychological, electrophysiological, and neuroimaging data strongly suggest the existence of a neurobiological basis for OCD [11-14]. Based on the effectiveness of SSRIs, the mainstream hypothesis of OCD etiology largely focused on the serotonin $(5-\mathrm{HT})$ system $[15,16]$. However, due to a high proportion of patients resistant to SSRI treatment [17], the focus has shifted towards the cortico-striatal-thalamo-cortical (CSTC) brain circuit. Neural and pathophysiological mechanisms linking the OCD with structures of the CSTC circuit have been further studied and some modifications to the model were recently proposed in the prominent Baxter's model [18], which is largely based on neuroimaging data. According to prevailing concepts, the CSTC circuit involves direct and indirect pathways that work in balance.

Glutamatergic excitatory signals from the orbitofrontal cortex (OFC) and anterior cingulate cortex (ACC) to the striatum lead through the direct pathway to increased inhibitory GABAergic signals to the globus pallidus interna (GPi) and substantia nigra ( $\mathrm{SNr}$ ). This, in turn, produces decreased inhibitory $\gamma$-aminobutyric acid (GABA) output from GPi and SNr to the thalamus resulting in increased thalamic stimulation of the cortex. In the normally functioning CSTC, the excitatory glutamatergic pathway is modulated by an inhibitory function of the indirect GABAergic projections. Through this indirect pathway, the striatal inhibition of the globus pallidus externa disinhibits the subthalamic nucleus, which then excites the GPi and SNr, leading to thalamic inhibition [19].

However, according to the aforementioned Baxter's model, an imbalance between the direct and indirect pathway may cause $O C D$ symptoms. Human and animal research has shown that excessive hyperactivation of the orbitofrontal-subcortical direct pathway together with hypoactivation of the basal ganglia indirect pathway generates increased anxiety and fear about one's safety. Through reinforcement, behavioral patterns relieving such constantly perceived threat become repetitive and are no longer under control of the will [19]. Multiple lines of evidence have shown an integral role of glutamate as the key neurotransmitter within the CSTC circuit [20]. Glutamatergic synaptic dysfunction within this area might, therefore, be implicated in the pathogenesis of OCD and related disorders $[16,21,22]$ as shown above for the CSTC's direct pathway that is glutamatergic.

Pathophysiology of OCD studied at the molecular level has focused on synaptic and extrasynaptic N-methyl-D-aspartate (NMDA) receptors [23]. The striatum, the major nucleus of the basal ganglia and 1 of the CSTS circuitry components, receives a large glutamatergic excitatory input carrying information about movements and associated sensory stimulation. This results in a large extracellular concentration of glutamate that can overcome neuronal and glial uptake homeostatic systems, hence allowing stimulation of extrasynaptic glutamate receptors.

Significant associations with OCD have been identified for genes including the glutamate receptor, ionotropic kainate 2 (GRIK2) [24] and glutamate transporter (SLC1A1) gene $[25,26]$. Mice with a deactivated SAPAP3 gene coding for a postsynaptic scaffolding protein at corticostriatal glutamatergic excitatory synapses developed facial lesions, repetitive grooming behaviors, and anxiety that could be reversed by SSRIs [27]. Glutamate also plays a significant role in the ACC, where high concentrations of glutamate receptors compared to other neurotransmitter binding sites can be found [28]. It is noteworthy that genetic research on OCD pathology has not stopped here; for example, a regulation of intracellular Ca2 + (RYR3), RNA-editing/protein modification (ADAR3), and immune response linked to microglial function (pre-B-cell leukemia homeobox) are recently studied areas [22].

The primal role of glutamatergic signaling system abnormalities in OCD pathogenesis has been supported by studies using proton magnetic resonance spectroscopy (1H-MRS) [29-31]. Rosenberg et al. [32] found higher striatal glutamate + glutamine (Glx) concentrations in pediatric OCD patients than in healthy controls. Interestingly, the increased levels normalized after treatment with SSRIs but not CBT despite its comparative effectiveness in symptoms reduction. In contrast to that, lower Glx concentrations were found in the ACC of both children [33] and female adult OCD patients [34] where the Glx levels correlated with symptoms severity. Moreover, reduced ACC Glx and increased caudate Glx in children with OCD is consistent with a previous report of inverse correlations between ACC and striatal volume [21]. It has been suggested that it is glutamate hyperactivity in the OFC that constitutes the substrate upon which SSRIs act to decrease such hyperactivity [35] (see also [13]).

Another piece of evidence came from a study of the relationship between polymorphism in genes involved in the pathophysiology of OCD (specifically, genes for serotogenic and glutamatergic pathways) and concentrations of neurometabolites in the ACC [36]. Significant associations between variations in 5 genes and concentrations of inositol, glutamate, glutamine, and choline in the ACC were found in children with OCD. The authors interpret this finding as a demonstration of the interaction between serotonin and glutamate pathways in OCD pathology. Conversely, Simpson et al. [37] reported no significant differences in glutamate levels in any of the 3 striatal regions (dorsal caudate, dorsal putamen, and ventral striatum) between OCD patients and matched healthy control subjects. It is noteworthy that the authors found negative results using a $1 \mathrm{H}-\mathrm{MRS}$ imaging technique with a relatively high spatial resolution at 3.0 T, while MRS at $1.5 \mathrm{~T}$ in another study revealed significant elevations in glutamatergic compounds. Therefore, at least some of these contradicting findings might be caused by differences in methodology [37].

Despite existing discrepancies in the previous studies of the association between the glutamatergic system dysfunction and OCD, it has been concluded that tonic-phasic dysregulation of Glx within the corticostriatal circuitry in OCD is plausible [30]. All this evidence has thus prompted increased effort to develop and evaluate agents modulating glutamatergic neurotransmission for more effective OCD treatment, although no controlled studies of such agents for standard OCD pharmacotherapy have yet been reported.

Finally, an interesting link between abnormalities of the glutamatergic system and OCD was proposed in a glutamate-based genetic immune hypothesis by Rotge et al. [25]. Genetic variability in gene SLC1A1 leads to functional alterations of the glutamate transporter excitatory amino-acid carrier 1 (EAAC-1), which results in increased (toxic) glutamate activity. Moreover, these functional alterations of EAAC- 1 are also responsible for immunopathological reactions after the exposure to Borna virus that consequently lead to structural and functional changes in thalamic nuclei that send glutamatergic projections to the ACC and OFC. The neurotoxicity 
effect of glutamate in these predisposed cortical areas is then responsible for the cognitive disruptions characteristic of OCD.

\section{Role of temporal lobe in OCD pathogenesis}

There is some evidence suggesting that apart from the CSTC circuitry an important role in the brain pathogenesis of OCD is played by the temporal lobe $(\mathrm{TL})$, which has attracted increased research attention in the past few years [38-40]. Different neuroimaging methods, e.g., magnetic resonance imaging (MRI) or single-photon emission computed tomography (SPECT), have already shown bilateral cortical abnormalities in the prefrontal and anterior-temporal regions together with perfusion deficits in frontotemporal regions and anterior striatum a few months after the onset of OCD. Moreover, clinical progress 6 months later was reflected by visible improvements of brain perfusion in the striatum area [41].

In a study comparing OCD twins with their healthy co-twins, the former scored higher for OCD symptoms and had increased fractional anisotropy in multiple regions of the right TL [42]. Furthermore, drug-naive OCD patients showed increased values of fractional anisotropy in the corpus callosum and associated areas of white matter in the bilateral superior temporal region [43]. The superior temporal region itself is connected with other structures implicated in OCD, such as the orbitomedial frontal areas, putamen, and nucleus caudate $[44,45]$. This leads to the conclusion that white matter of the TL might play an important role in OCD neuropathology [46]. In a follow-up twin study, a significant interaction effect of sex and OCD symptoms on the grey matter volume was found [47]. While larger grey matter volume in the right middle temporal gyrus was revealed in males scoring high on OCD symptoms, it was reduced in high-scoring females. Interestingly, exactly the opposite sex-related pattern was observed for the right precuneus volume. Thus, the authors argue that the differences in OCD brain-related changes for males and females may hide the main effect of OCD symptoms on the brain volume.

Another study focused on a potential relationship between morphological abnormalities of the superior temporal gyrus (STG), which may be involved in OCD pathophysiology, visuospatial function, and clinical symptoms [48]. A significant volume reduction in the grey matter of the anterior STG in patients compared with healthy volunteers was observed, but this reduction did not correlate with cognitive impairment and clinical symptoms assessed by a psychometric battery. Therefore, the link between a reduction in brain volume in specific areas and cognitive impairment observed in OCD patients warrants further research (see also [49]).

Based on a few neuroimaging studies, abnormalities in the amygdala-hippocampus complex (AHC), a specific region of the $\mathrm{TL}$, seem to be implicated in the pathophysiology of pharmacoresistant OCD [50]. This is not so much surprising since the AHC has strong connections with the OFC [51] and together are thought of as structures connecting the brain regions that modulate information involved in the initiation of behavioral responses without conscious awareness [48]. As demonstrated by Atmaca [52], the mean left and right hippocampal and amygdala volumes were smaller in OCD refractory patients than in healthy controls, and even more, the severity of their symptoms was correlated with the left hippocampus volume. Interestingly, pharmacological agents effective in OCD treatment (e.g., SSRIs) exert their effects on amygdala re- ceptors [53]. Furthermore, a network-based statistical analysis has recently revealed decreased structural connectivity among orbitofrontal, striatal, insula, and temporolimbic areas with important local alternations for the amygdala and temporal pole in patients with OCD as indicated by graph theoretical measures [54].

An intriguing association between abnormalities in TLs and OCD symptoms has been demonstrated in a study focusing on the prevalence and severity of clinically significant obsessions and compulsions in a large sample of patients with temporal lobe epilepsy (TLE) [55]. Compared with the general population, the TLE patients reported OCD symptoms at a higher prevalence rate. Specifically, $22 \%$ of the patients scored in the clinical range on the Obsessive Compulsive Inventory, which is considerably higher than $2.5 \%$ observed in the general population. This was further corroborated by Monaco et al. [56], who found that $14.5 \%$ of TLE patients also had a diagnosis of OCD. Moreover, it has been argued that brain structures and neurobiological mechanisms responsible for compulsions are different from those associated with obsessions and are particularly vulnerable in TLE patients [55]. It is noteworthy that a complete remission of OCD symptoms after epilepsy surgery has been observed [57, 58].

Based on evidence from quantitative electroencephalography (QEEG), the existence of 2 subtypes of OCD patients meeting the DSM-III-R diagnostic criteria has been suggested [17]. While cluster 1 was characterized by excess relative power in theta (especially in the frontal and frontotemporal regions), cluster 2 could be described by increased relative power in alpha within bipolar temporal and frontotemporal regions. Furthermore, $80 \%$ of patients from cluster 1 were found to be nonresponders to drug treatment by SSRIs, but exactly the opposite pattern was found in cluster 2 , where $82.4 \%$ of members responded well to medication. Thus, the author, later supported by others [59], argues that despite common symptoms at least 2 pathophysiological subgroups showing a differential response to treatment with SSRIs exist within the OCD population.

The neurophysiological abnormality of TL activity in OCD patients was later confirmed in another study [60]. During TL activation by olfactory stimulation, a power increase was detectable in the slower beta frequencies in healthy subjects. In contrast to that, the OCD patients' EEGs showed no change or even a slight decrease. Moreover, increase in delta- 1 and decrease in alpha- 2 power at rest was evident when comparing OCD patients with heatlhy controls.

Structural and functional changes within the TL in OCD patients are also reflected in cognitive, or more precisely, memory deficits. One of the cognitive theories conceptualized OCD as a fundamental disorder of implicit (frontostriatal) information-processing systems that is compensated by aberrant recruitment of limbic structures centrally involved in explicit information processing (hippocampal hyperfunction vs. striatum hypofunction). These failures in implicit (nonconscious) processing may, therefore, lead to the clinical expression of OCD symptoms such as intrusive repetitive cognitions and associated cognitive anxiety that healthy subjects are able to put to rest [61]. As predicted by the theory, significant implicit sequence learning deficits in OCD versus healthy subjects were demonstrated in a behavioral experiment adopting a serial reaction time paradigm [62]. The authors conclude that in order to mask the implicit information-processing deficit (frontostriatal 
dysfunction) in OCD patients, explicit information-processing networks including medial temporal structures are engaged in a compensatory fashion (see also [63]).

The switch between different memory processes used as a compensatory mechanism in a range of impairments across neurodevelopmental disorders including OCD has been recently demonstrated by Ullman and Pullman [64], who based their concept on an extensive review of existing behavioral, electrophysiological, and neuroimaging evidence. Since OCD symptoms might be partly explained by impairments in procedural memory, they hypothesize that patients might use declarative memory to fully or partly compensate the impairment in procedural learning tasks. This is supported by positron emission tomography (PET) studies that report more activation in declarative memory brain substrates in $\mathrm{OCD}$ patients $[61,62]$. Moreover, a negative correlation has been found between the volume of hippocampal and medial TL regions and the intensity of obsessive thoughts and actions [65].

However, others have challenged the model suggesting that deficiencies of striatal recruitment or thalamic gating in the context of implicit learning are not necessarily present in OCD [40]. Instead, they stress the aberrant hippocampal activation that can be consistently observed in the absence of deficient striatal recruitment across samples and symptom types of OCD. Thus, instead of the view that hippocampal involvement is attributable to striatal deficiency, it is possible that the aberrant hippocampal function itself has a principal role in OCD. In regards to the evidence of dysbalance between frontostriatal (implicit) and frontohippocampal (explicit) information-processing systems in OCD, some authors call for larger-scale human neuroimaging studies to support functional connectivity analyses [66] that are already well-established in nonhuman research [67].

The neuropsychological model of OCD is well-extended by a hypothesis of a potentially close relationship between checking rituals and neuropsychological dysfunction related to memory. Interesting results have come from the comparison of different $O C D$ subtypes showing that more severe memory deficits were experienced by people with obsessions/checking than people with cleanliness/ washing rituals [13]. One of the proposed etiologies for checking behavior is the inability to accurately recall whether an activity has been completed correctly [68]. Paradoxically, repeating checking behaviors bring even more distrust in one's own memory [69-71]. Therefore, it is self-confidence in memory rather than memory per se that seems to be more impaired [72]. Checkers demonstrate poor general memory compared to washers, which is related inhibition deficits [73]. On the other hand, washers perform significantly better than checkers on a pattern of recognition task and show a faster motoric response during a planning task [74].

Finally, an association between checking symptoms and spatial memory dysfunction has been found in several studies $[75,76]$. In line with this evidence, an intriguing hypothesis linking anxiety and spatial memory deficits with specific TL regions in patients with checking symptoms has been proposed [77]. It is suggested that lower performance on spatial working memory tests in those patients might be explained by higher anxiety levels that can subsequently worsen the symptoms. At the neural level, the authors hypothesize interactions between the cortico-basal ganglia circuits and the amygdala and/or ventral hippocampal node, which fits with the above-mentioned CSTC model extended to temporal regions. Furthermore, this concept makes a comprehensive connection between anxiety, repetitive behaviors, and cognitive deficits.

In this perspective, it is noteworthy that the neural circuit going from the prefrontal cortex (PFC) to the hippocampus, as well as connections between the hippocampus and amygdala, are, among others, glutamatergic. It may, therefore, be speculated that pharmacological agents affecting the glutamatergic system (e.g., memantine as an NMDA antagonist) could lower the initially increased excitation potential of these neural pathways that would eventually lower the symptoms of OCD.

\section{Do Different OCD Subtypes have Specific Neural Correlates?}

Neuroimaging research on brain structural changes in OCD patients has mostly provided consistent results [78]. Compared to a control group, OCD patients show alternations of grey matter volume in several brain regions, including the medial frontal gyrus, medial OFC, ventral putamen, and the anterior cerebellum [38]. Moreover, intriguing neuroanatomical alternations have been observed for individual subtypes as well, which confirms the hypothesis that each OCD subtype with specific symptomatic dimensions has its own neural signature. While significant associations were found between contamination/cleaning symptoms and the reduced dorsal caudate, scores on harm/checking obsessions were, on the other side, negatively correlated with the grey and white matter volume in anterior parts of TLs [79]. These regions including the amygdala and parahippocampal cortices are known to have connections with the hippocampus and associated areas.

Such findings are interesting in the context of the hypothesized important role of TL abnormalities in OCD neuropathology. It is especially the amygdala, a structure predominantly involved in fear and anxiety processing, whose functional alternations seems to contribute to observed differences between specific OCD subtypes. A significant correlation was found between the severity of aggression/checking symptoms of OCD patients and the amygdala activation representing an abnormal fear reaction in response to fearful faces [80]. Corroborating results were reported in another study of patients with prominent aggressive/checking symptoms who showed reduced volume in the right amygdala [38]. However, others have localized brain structural changes associated with these symptoms to other regions (e.g., the insula and putamen [81] or the right posterior cingulate and medial occipital cortices [82]).

Although several different approaches were taken to categorize a clinically heterogeneous presentation of $O C D$, research has recently focused on a classification separating OCD subjects in 2 specific groups: those with autogenous and reactive obsessions [83]. According to this conceptualization based on symptomatology, autogenous obsessions are relatively independent on perceived external triggers and/or come abruptly into consciousness without any link to the environmental context of present stimuli. Based on their content (mainly immoral, sexual, aggressive, etc.) the autogenous obsessions are ego-dystonic and perceived as aversive. In contrast, reactive obsessions are triggered by external objects or clues in the environment. The evoking stimuli are perceived as realistic, therefore less ego-dystonic, leading to rational coping 
mechanisms. Thoughts about contamination, accident, asymmetry, or loss are among the most common reactive obsessions. Moreover, following studies have shown that a distinction between the 2 subtypes exists not only in the clinical variables but also in a sociodemographic and neurobiological profile.

Specifically, autogenous obsessions were associated with decreased $\mathrm{N}$-acetyl-aspartate levels in the limbic medial TL [84] and other TL structural alternations. This is in line with a study exploring neural correlates of dysfunctional beliefs associated with OCD [85]. In normal subjects, the authors observed significant negative correlations between anterior temporal lobe (ATL) volume and scores on the over importance/need to control thoughts domain of the Obsessive Beliefs Questionnaire-44, which can be attributed to autogenous obsessions. Moreover, ATL volume was bilaterally smaller in OCD patients than in the controls, especially those from a low-belief group. Corroborating results from another study showed that autogenous OCD patients had a smaller left anterior TL than healthy controls, while bilaterally larger volumes in the putamen were observed in reactive patients [39]. Moreover, both patients subgroups compared to control subjects were observed to have a smaller right middle temporal gyrus. The authors consider these results as a neurobiological support for the above-mentioned OCD classification [83] and suggest that the 2 types of obsessions have a distinct neural substrate.

Nevertheless, autogenous and reactive obsessions are not mutually exclusive categories as patients with a mixture of obsessions can be found as well. For example, the harm/checking thoughts that were found to negatively correlate with the grey matter of the ATL [79] also partially overlap with autogenous obsessions [39].

\section{Glutamatergic agents in OCD therapy}

Several studies have already provided evidence showing the effectiveness of medication acting on the glutamatergic system in the treatment of pharmacoresistant OCD [86-88]; for a review, see - Table 1. First, there is riluzole, which exerts a neuroprotective effect, inhibits the glutamate release, and blocks GABA reuptake [89]. It has also proven a therapeutic effect when added to SSRIs [88, 90]. Moreover, riluzole action through neuroglial systems is noteworthy, as it apparently decreases the activity of glutamatergic transporters GLAST, GLT1, or EAAC1, which may possess a specific effect in OCD [91-93].

Ketamine, which is a noncompetitive antagonist of the NMDA receptor, is primarily tested for its rapid antidepressant effect within $40 \mathrm{~min}$ following an intravenous infusion $[94,95]$. Moreover, there are sporadic studies demonstrating an anti-obsessional effect of ketamine infusion in unmedicated OCD individuals that is as rapid as in depression and can last for a few days [96]. This rapid effect was also confirmed in some patients with intrusive thoughts in a randomized controlled crossover trial on 15 adults with OCD $[97,98]$. Finally, Bloch et al. [99] found statistically significant improvement in OCD symptoms over 1-3 days following ketamine infusion compared with baseline.

Similarly, another drug with a potential benefit for OCD patients is topiramate, an anticonvulsant and antagonist of $\alpha$-amino-3hydroxy-5-methyl-4-isoxazolepropionic acid (AMPA)/kainate receptors [100]. However, very few double-blinded placebo-con- trolled studies have been conducted on this drug. Nevertheless, promising results were reported by Berlin et al. [101], who found its predominantly anticompulsive activity. Therefore, topiramate may potentially be used in reactive forms of OCD, while the therapeutic effect of memantine is expected mostly in autogenous OCD. An explanation for positive outcomes after treatment with topiramate can be potentially rooted in its anti-epileptogenic action, which is mainly due to the impact it has on glutamatergic receptors, but also its capacity to alternate the function of sodium and calcium channels and GABA-A receptors.

Another anti-epileptic drug with a positive effect, when used as an adjuvant medication to treatment with SSRIs and clomipramine, is lamotrigine. Several case studies [102-104] and 1 double-blinded placebo-controlled study has already reported encouraging therapy outcomes from treatment of pharmacoresistant OCD with lamotrigine [105]. This drug can influence OCD symptoms through the glutamatergic system indirectly as it decreases the glutamate release by acting on presynaptic voltage-gated sodium channels in the hippocampus, amygdala, and striatum [106, 107]. In addition, other authors argue that release of glutamate is in the case of lamotrigine caused by other pharmacodynamic mechanisms $[108,109]$. Thus, more double-blinded studies need to be done in order to gain full understanding.

It has been suggested that damage to glial cells by oxidative stress is at the root of various neuropsychiatric disorders including OCD [110-112]. Decreasing the levels of glutamate N-acetylcysteine (NAC) helps keep glutathione within glial cells, which decreases their vulnerability to oxidative damage [112]. Furthermore, NAC increases the level of cystine in the brain, which leads to an exchange of intracellular glutamate with cystine due to activation of cystine-glutamate antiporter. Increased levels of extracellular glutamate then activate inhibitory metabotropic glutamate receptors (mGluR2/3) on presynaptic neurons, which results in a decrease of glutamatergic excitation neurotransmission [113]. In association with CSTC pathology in OCD, there is an important finding that NAC increases dopaminergic neurotransmission in the striatum by facilitating the release of vesicular dopamine in striatal neurons [114]. This ability to alternate dopamine levels, together with the finding that NAC restores extracellular glutamate homeostasis in the nucleus accumbens [115], might explain the positive effect of NAC in OCD, but also in addictive and impulse control disorder (e.g., trichotillomania) [116].

Antibiotic used to treat tuberculosis, D-cycloserine (DCS), also acts as a partial agonist of NMDA receptors. In the case of low glycine levels, DCS is able to facilitate NMDA receptors functioning, but when glycine levels are sufficient, DCS acts as their antagonist $[117,118]$. Animal studies of conditioned fear have demonstrated that stimulating the NMDA receptor at the glycine site in the amygdala by DCS plays a significant role in fear extinction. In compliance with the partially agonistic action of DCS, its effect on the psychotherapeutic process might be understood through increasing neuroplasticity (enhancing the NMDA receptor functioning) or fear memories reconsolidation (reducing the NMDA receptor functioning) $[117,119]$. However, as shown in $>$ Table $\mathbf{1}$, clinical studies failed to show significant differences between the experimental and placebo group, which may be due to the fact that the exposure and response prevention therapy (ERP) that was used in both con- 
- Table 1 Review of studies testing the effect of augmentation drugs in pharmacoresistant OCD.

\begin{tabular}{|c|c|c|c|c|c|c|}
\hline Augmentation drug & Dose & Duration & $\begin{array}{l}\text { Target/ } \\
\text { control } \\
\text { group size }\end{array}$ & Main effect & Notes & $\begin{array}{l}\text { Refer- } \\
\text { ence }\end{array}$ \\
\hline \multirow[t]{10}{*}{ D-cycloserine } & $125 \mathrm{mg} / \mathrm{ERP}$ & $\begin{array}{l}10 \text { ERP } \\
2 \text { ERP/week }\end{array}$ & $14 / 11$ & $\mathrm{DCS}=\mathrm{PLA}$ & $\begin{array}{l}\text { Obsession-related fear } \\
\text { ratings declined more } \\
\text { rapidly in the target group } \\
(\mathrm{p}<0.02)\end{array}$ & {$[123]$} \\
\hline & $250 \mathrm{mg} / \mathrm{ERP}$ & $\begin{array}{l}12 \mathrm{ERP} \\
1 \mathrm{ERP} / \text { week }\end{array}$ & $12 / 12$ & $\mathrm{DCS}=\mathrm{PLA}$ & & [154] \\
\hline & $100 \mathrm{mg} / \mathrm{ERP}$ & $\begin{array}{l}10 \mathrm{ERP} \\
2 \mathrm{ERP} / \text { week }\end{array}$ & $10 / 13$ & $\mathrm{DCS}>\mathrm{PLA} * * *$ & & [121] \\
\hline & $125 \mathrm{mg} / \mathrm{ERP}$ & $\begin{array}{l}10 \text { ERP } \\
2 \text { ERP/week }\end{array}$ & $10 / 12$ & $\mathrm{DCS}>\mathrm{PLA} * * *$ & $\begin{array}{l}\text { The target group recovered } \\
2.3 \text { times faster }\end{array}$ & [122] \\
\hline & $\begin{array}{l}\text { weight-adjusted } \\
25 \text { or } 50 \mathrm{mg} / \text { ERP }\end{array}$ & $\begin{array}{l}7 \mathrm{ERP} \\
1 \mathrm{ERP} / \text { week }\end{array}$ & $15 / 15$ & $\mathrm{DCS}=\mathrm{PLA}$ & The effect for CY-BOCS & [155] \\
\hline & $\begin{array}{l}\text { weight-adjusted } \\
25 \text { or } 50 \mathrm{mg} / \text { ERP }\end{array}$ & $\begin{array}{l}7 \text { ERP } \\
1 \text { ERP/week }\end{array}$ & $15 / 15$ & $\mathrm{DCS}=\mathrm{PLA}$ & The effect for CY-BOCS & [156] \\
\hline & $50 \mathrm{mg} /$ day & $\begin{array}{l}5 \mathrm{ERP} \\
1 \mathrm{ERP} / \text { week }\end{array}$ & $64 / 64$ & $\mathrm{DCS}=\mathrm{PLA}$ & $\begin{array}{l}\text { Significantly greater } \\
\text { proportion of antidepres- } \\
\text { sant-free patients in the } \\
\text { target group achieved } \\
\text { remission }(p=0.008)\end{array}$ & [124] \\
\hline & $50 \mathrm{mg} / \mathrm{ERP}$ & $\begin{array}{l}10 \mathrm{ERP} \\
1 \mathrm{ERP} / \text { week }\end{array}$ & $13 / 14$ & $\mathrm{DCS}>\mathrm{PLA} * *$ & $\begin{array}{l}\text { The effect for CY-BOCS: } \\
\text { homework compliance not } \\
\text { associated with treatment } \\
\text { outcome in the placebo } \\
\text { conversely to treatment } \\
\text { group }\end{array}$ & [157] \\
\hline & $\begin{array}{l}\text { weight-adjusted } \\
25 \text { or } 50 \mathrm{mg} / \text { ERP }\end{array}$ & $\begin{array}{l}7 \text { ERP } \\
1 \text { ERP at least } \\
\text { every } 5 \text { days }\end{array}$ & $70 / 72$ & $\mathrm{DCS}=\mathrm{PLA}$ & & [120] \\
\hline & 125 mg/day & $\begin{array}{l}6 \mathrm{ERP} \\
1 \mathrm{ERP} / \text { week }\end{array}$ & $19 / 20$ & $\mathrm{DCS}=\mathrm{PLA}$ & $\begin{array}{l}\text { Significant effect found only } \\
\text { for contamination/cleaning } \\
\text { subgroup }(p=0.033)\end{array}$ & [125] \\
\hline Glycine & $60 \mathrm{~g} /$ day & 12 weeks & $5 / 9$ & $G L Y=P L A$ & $\begin{array}{l}\text { Close-to-significant effect } \\
(p=0.053)\end{array}$ & [126] \\
\hline Ketamine (infusion) & $\begin{array}{l}0.5 \mathrm{mg} / \mathrm{kg} \text { (no } \\
\text { other medica- } \\
\text { tion) }\end{array}$ & 1 week & $8 / 7$ & $\mathrm{KET}>\mathrm{PLA} *$ & $\begin{array}{l}\text { Full response } \mathrm{e}^{\mathrm{b}} \text { in } 50 \% \text { of the } \\
\text { target group vs } 0 \% \text { of the } \\
\text { placebo group }\end{array}$ & [97] \\
\hline Lamotrigine & $100 \mathrm{mg} /$ day & 16 weeks & $17 / 16$ & LAM $>$ PLA $* * *$ & $\begin{array}{l}\text { Improvement in affective } \\
\text { symptoms (HRSD) too }\end{array}$ & [105] \\
\hline \multirow[t]{3}{*}{ Memantine } & $\begin{array}{l}\text { mean final dose } \\
18.0 \mathrm{mg} / \text { day }\end{array}$ & $\begin{array}{l}62 \text { days } \\
\text { (mean) }\end{array}$ & $22 / 22$ & $\mathrm{MEM}>\mathrm{PLA}^{\mathrm{a}}$ & $\begin{array}{l}\text { Clinical improvement in the } \\
\text { target group } 27.0 \% \text { (vs. } \\
16.5 \% \text { in the placebo group) }\end{array}$ & [131] \\
\hline & 20 mg/day & 8 weeks & $19 / 19$ & MEM $>$ PLA $* * *$ & $\begin{array}{l}\text { More patients in the target } \\
\text { group achieved remission }\end{array}$ & [133] \\
\hline & $5-10 \mathrm{mg} /$ day & 12 weeks & $14 / 15$ & MEM $>$ PLA* & $\begin{array}{l}\text { Full response }{ }^{b} \text { more likely in } \\
\text { the target group }\end{array}$ & [132] \\
\hline \multirow[t]{5}{*}{$\mathrm{N}$-acetylcysteine } & $2.4 \mathrm{~g} /$ day & 12 weeks & $19 / 20$ & $\mathrm{NAC}>\mathrm{PLA}^{* *}$ & & [158] \\
\hline & $3 \mathrm{~g} /$ day & 16 weeks & $20 / 15$ & $N A C=P L A$ & $\begin{array}{l}\text { Significant effect observed } \\
\text { for the compulsions subscale } \\
(p=0.013)\end{array}$ & [159] \\
\hline & 2 g/day & 10 weeks & $22 / 22$ & $\mathrm{NAC}>\mathrm{PLA}^{*}$ & & [160] \\
\hline & $3 \mathrm{~g} /$ day & 16 weeks & $16 / 19$ & $N A C=P L A$ & $\begin{array}{l}\text { NAC superior to placebo in } \\
\text { reducing anxiety symptoms } \\
(\mathrm{p}=0.02)\end{array}$ & [161] \\
\hline & $2.4 \mathrm{~g} /$ day & 10 weeks & $18 / 11$ & $\mathrm{NAC}>\mathrm{PLA} *$ & & [162] \\
\hline Riluzole & 100 mg/day & 12 weeks & $29 / 30$ & $\mathrm{RIL}=\mathrm{PLA}$ & Effect for CY-BOCS & [163] \\
\hline
\end{tabular}


- Table 1 Review of studies testing the effect of augmentation drugs in pharmacoresistant OCD.

\begin{tabular}{|c|c|c|c|c|c|c|}
\hline Augmentation drug & Dose & Duration & $\begin{array}{l}\text { Target/ } \\
\text { control } \\
\text { group size }\end{array}$ & Main effect & Notes & $\begin{array}{l}\text { Refer- } \\
\text { ence }\end{array}$ \\
\hline & $100 \mathrm{mg} /$ day & 12 weeks & $19 / 18$ & $\mathrm{RIL}=\mathrm{PLA}$ & $\begin{array}{l}\text { Close-to-significant improve- } \\
\text { ment of obsessions in the } \\
\text { outpatient subsample } \\
(p=0.056)\end{array}$ & [90] \\
\hline \multirow[t]{3}{*}{ Topiramate } & $\begin{array}{l}\text { mean dose } \\
180.15 \mathrm{mg} / \text { day }\end{array}$ & 12 weeks & $20 / 21$ & TOP $>$ PLA $* * *$ & & [164] \\
\hline & $\begin{array}{l}\text { mean dose } \\
177.8 \mathrm{mg} / \text { day }\end{array}$ & 12 weeks & $13 / 14$ & $\mathrm{TOP}=\mathrm{PLA}$ & $\begin{array}{l}\text { Treatment effect on the } \\
\text { compulsions }(p=0.014) \text {, but } \\
\text { not obsessions }(p=0.99)\end{array}$ & [101] \\
\hline & $\begin{array}{l}\text { mean dose } \\
137.5 \mathrm{mg} / \text { day }\end{array}$ & 12 weeks & $13 / 14$ & $\mathrm{TOP}=\mathrm{PLA}$ & $\begin{array}{l}\text { Significant effect observed } \\
\text { for the first } 2 \text { months } \\
(p=0.01)\end{array}$ & [165] \\
\hline \multicolumn{7}{|c|}{$\begin{array}{l}\text { The level of statistical significance: }{ }^{*} \mathrm{p}<0.05,{ }^{*}{ }^{*} \mathrm{p}<0.01,{ }^{*}{ }^{*} \mathrm{p}<0.001 \text {; a single-blinded case-control study, no statistical significance was } \\
\text { reported; b full-response: } \geq 35 \% \text { Y-BOCS reduction; CY-BOCS: Children's Yale-Brown Obsessive Compulsive Scale (i.e., used in studies conducted on } \\
\text { children patients); ERP: exposure with response prevention; HRSD: Hamilton Rating Scale for Depression. }\end{array}$} \\
\hline \multicolumn{7}{|c|}{$\begin{array}{l}\text { Only the studies on glutamatergic agents using a control group were included in the table. Unless otherwise specified, these are double-blinded } \\
\text { placebo-controlled studies on adult OCD patients that employed the Y-BOCS to measure the effect of augmentation pharmacotherapy on obsessive- } \\
\text { compulsive symptoms. The target/control group size column reports the number of participants in either of the groups at the end of the study. The } \\
\text { main effect shows whether the Y-BOCS score was significantly higher in the treatment group than in the placebo group and the level of statistical } \\
\text { significance }\end{array}$} \\
\hline
\end{tabular}

ditions leads most likely alone to substantial decrease in the YaleBrown Obsessive Compulsive Scale (Y-BOCS) score [120]. Nevertheless, a few studies have shown that DCS considerably accelerates the onset of the ERP effect and lowers distress associated with exposures [121-123].

Based on the literature on DCS, there are many unresolved questions that remain. For instance, how is the therapeutic effect of fear memory extinction alternated by adding antidepressants to DCS medication [124]? Additionally, how is the effect on distress differentiated from the own memory effect depending on the dose level? These pharmacokinetic questions ought to be resolved considering different dosing schemes, which have been until recently below the lower dose in antibiotic therapy (see > Table 1). Another interesting point is the potential effect of adjuvant therapy (antidepressant + DCS) in patients with a cleaning/contamination OCD subtype [125].

An alternative approach to influence the glutamatergic system in OCD therapy is to medicate with glycine. This amino acid has been shown to be active in forebrain structures, where it activates NMDA receptors function. Besides that, it also possesses a neuromodulating effect in the hippocampus, hence its plausible role in learning and memory functions. Currently, there is just 1 placebocontrolled study that proves clinical efficacy of glycine [126].

There is also bitopertine (glycine transporter 1 inhibitor), an experimental drug, currently in the third stage of clinical testing [127], which is a glycine reuptake inhibitor (i.e., the glycine levels increase upon administration of bitopertine). Therefore, bitopertine is another drug that might potentially reduce OCD symptoms through its impact on the glutamatergic system. Although the exact pharmacodynamic effect of both glycine and bitopertine remains unclear, an activity similar to memantine might be expected.

Finally, among several other drugs affecting the glutamatergic system, which are tested for their therapeutic effect in OCD, should be mentioned rapastinel. It is a partial agonist at the glycine functional site of the NMDA receptor [128]. Most recently, there has been a study on a negative allosteric modulator of mglu5 receptors, mavoglurant [129].

\section{Treatment potential of memantine-drug of choice for checkers?}

There is an extensive line of evidence showing benefits of adjuvant medication with memantine in the treatment of OCD resistant to other drugs [22, 87, 88, 130-132]. For example, when memantine was added to fluvoxamine treatment in a randomized double-blinded study, significantly more patients from the combined medication group than from the placebo group (17 vs. 6) achieved remission, while the frequency of side effects was comparable between the 2 groups [133]. These results clearly show that memantine addon significantly improved the treatment outcomes in moderate to severe OCD subjects, which was corroborated in a similar study reporting a significant decrease in both symptoms and illness severity in a group of OCD patients co-medicated with memantine compared to placebo [132].

Pharmacodynamics of this agent may be explained in light of the aforementioned findings that are in support of the original CSTC model extended of the glutamatergic system [35, 134-136]. Furthermore, another piece of evidence coming from the research of intractable OCD also points to the TL [52], which is also linked to the glutamatergic system and sensitive to its functional changes [137].

Besides the potential of memantine as an antagonist of the NMDA receptor to improve excitability of glutamatergic neurons connected in the CSTC circuitry, also noteworthy is its capacity to impact on several structures of the TL and their glutamatergic internal connections and inputs/outputs to other regions involved in OCD and related neuropsychological symptoms. Considering both 
the structural and functional abnormalities localized in the TL that are characteristic for $O C D$, and particularly some of its subtypes (e.g., checkers), here we propose a novel hypothesis that use of memantine with a glutamatergic or, more specifically, de-excitation impact on these structures may have a significant therapeutic outcome (see $>$ Fig. $\mathbf{1}$ ). The rationale for that may be found when cognitive (a compensation of implicit memory by the explicit one; impaired spatial working memory), neurochemical, and neuroanatomical aspects of the illness are linked together into 1 theoretical model (see description for figure).

Moreover, it can be supported by evidence coming from research focusing on connectivity between different brain regions after administration of memantine. For example, resting state funtional MRI (fMRI) following subchronic treatment by memantine revealed significant decreases in functional connectivity among the hippocampal and frontal cortical structures (prelimbic, cingulate) indicating a loss of connectivity. Besides that, memantine also caused functional and ultrastructural alterations in these regions, and moreover, induced behavioral effects comparable to other NMDA antagonists [138].

A study of changes in cerebral glucose metabolism after memantine therapy of patients suffering from post-traumatic cognitive impairment found significantly decreased glucose metabolism in several brain structures including the cerebellum, left thalamus, left olfactory and right middle temporal gyrus, and the right amygdala and insula [139]. On the other hand, increased glucose metabolism was detected in the inferior and middle frontal gyri and the inferior parietal lobule of the left hemisphere. This is an interesting finding because it confirms the de-excitation effect of memantine on specific regions of the TL that are associated with in- creased activity of explicit memory. Although more studies would be necessary to confirm the findings mentioned above, it can be preliminarily stated that memantine is able to regulate increased activity in the regions that form a neural substrate of pharmacoresistancy in OCD and also interlink neuropsychological and symptomatological (checking rituals, autogenous obsessions) aspects of OCD.

In regards to the above-mentioned relation between TLE and $O C D$, the effect of memantine on the reduction of experimentally induced epileptogenic activity of the TL is worthy of interest $[140,141]$. Besides that, memantine was also found to improve cognitive deficits (spatial memory) associated with TLE $[142,143]$. Moreover, other studies have reported an even more pronounced effect of substance IEM-1913 (1-amino-4-(1-adamantane-amino)butane dihydrochloride), which, apart from being an antagonist of NMDA receptors as memantine, also acts antagonistically on AMPA receptors [144]. Thus, it might be promising in future research of experimental models of OCD to extend the focus from memantine to other drugs affecting the glutamatergic excitation-inhibition balance of the temporal neural structures.

Another region that is worth focusing on in regards to memantine therapy is the anterior part of the TL. As stated above, ATL volume has been found to be bilaterally smaller in autogenous as well as harm/checking obssesions $[39,79]$. The temporal pole that is a part of the ATL has strong connections with the amygdala and orbital PFC and plays a crucial role in a multimodal analysis of social and emotional processes. Specifically, the right temporal pole is related to socially relevant, personal, and episodic memories [145-149]. Thus, it is possible that the emotionally charged content of autogenous obsessions that are incongruent with the actual context may

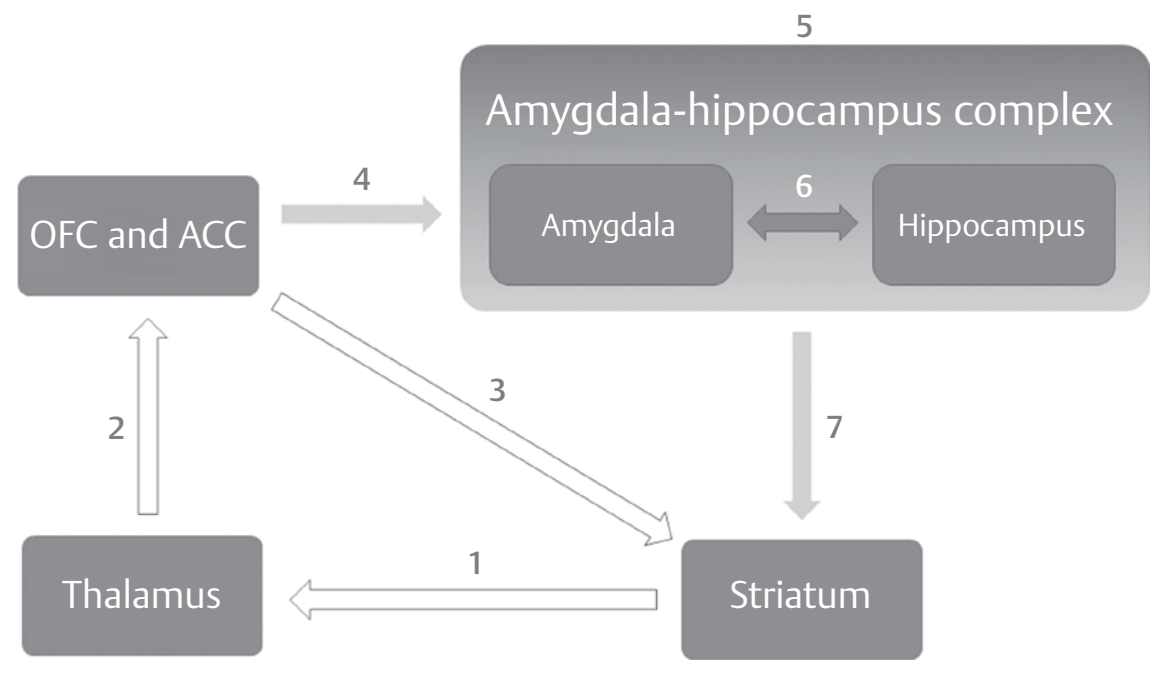

Fig. 1. Potential effect of memantine. By its de-excitation effect memantine decreases the activity of direct pathway of the CSTC circuit (1, 2, 3), which results in lower pathological activity of the orbitofrontal cortex (OFC). Memantine might also probably modulate connectivity between the OFC, anterior cingulate cortex (ACC), and amygdala-hippocampus complex (AHC) (4). Direct action of memantine on the temporal lobe structures, especially the AHC might also be expected (5). Within the AHC, memantine could alternate the dysbalanced activity between the amygdala and hippocampus, which would explain the positive changes in anxiety, as well as in the impaired or alternated cognitive performance characteristic of OCD (6). Another expected effect of memantine in OCD is removal of disturbing interference between the AHC and striatum that could improve performance of implicit memory. Besides that, memantine may improve functioning of the striatal memory system by decreasing levels of extracellular glutamate which disrupts functioning of the striatum (7). 
be co-created by disinhibition of the temporal pole through a dysfunctional connection with the PFC and amygdala (i.e., the regions involved in OCD pathogenesis). We suggest that future studies testing this hypothesis would be required. Using a connectivity matrix, this research could also demonstrate whether eventually pathological circuits of the mentioned brain regions may be affected by memantine. In addition, OCD, both reactive and autogenous, is associated with a smaller right temporal gyrus, where memantine decreases the glucose metabolic rate, as shown above [139]. In this perspective, future pharmaco-fMRI and pharmaco-EEG studies of memantine impact on interconnections between the TL and associated neuroanatomical structures could be promising.

The reported evidence that memantine causes frontohippocampal disconnectivity is in line with its hypothesized higher effectiveness in pharmacoresistant checkers characterized by frontohippocampal compensation (explicit memory) of otherwise impaired frontostriatal connection (implicit memory), impaired spatial working memory, and higher intractable anxiety. More precisely, this combined treatment would benefit especially those cases where OCD is linked to a cognitive deficit caused by dysfunction of the TL regions. This is supported by several anecdotal reports of benefits of memantine treatment for patients with checking rituals, both children [130] and adults [150,151].

Furthermore, we may assume that a positive response to memantine should be followed by changes in QEEG parameters in terms of a lower proportion of slow-wave activity in the TL. Finally, the weakest effect of memantine adjuvant therapy may be expected in washers. This is based on a premise that people with hygienelinked obsessions and associated cleanliness/washing rituals probably differ in the extent of specific cognitive functions impairment as compared to checkers. Besides, as it follows from this review, washing rituals belong to reactive obsessions that are related to alternations in different brain structures (e.g., the putamen) compared to autogenous obsessions.

In this perspective, we find it essential to study further the structural, functional, and effective connectivity between the ventral hippocampus and PFC together with other crucial neural structures related to OCD pathology. Detailed neuroanatomical and neuropharmacological research in this area ought to explain, among others, the co-occurrence of increased use of explicit memory in checkers that mainly originates in the dorsal hippocampus. It would be of high interest to focus on the question of whether memantine affects the associated structures of the TL (i.e., amygdale-hippocampal complex) directly and/or through the CSTC circuit. In fact, memantine could have a de-excitation effect on the increased activity of the direct pathway in the CSTC circuit, which projects into the cortex that would subsequently alternate connectivity between the PFC and TL.

\section{Conclusion}

In this review, we focused on specific neuroanatomical and neuropsychological mechanisms, which would complete the classic CSTC model of OCD. The dysfunction of TL regions could explain both the OCD pharmacoresistancy to standard monoaminergic antidepressants and certain symptomatic manifestations of this illness. We suggest that when in connection with the glutamatergic system and its own role in OCD neuropathology, our perspective may provide an explanation for a potential benefit of NMDA antagonist memantine in a treatment of intractable OCD. We argue that the effect of memantine may be understood through functional disconnection of crucial frontal regions with the hippocampus (i.e., structures that are associated with OCD pathogenesis) (see $>$ Fig. 1). Connections within these structures can be better evaluated in the context of a compensational mechanism substituting implicit memory impairments with the higher engagement of explicit memory. These functional abnormalities together with the effect on the amygdala may clarify the decrease of anxiety associated with doubts over activities that are controlled by implicit memory (checking rituals).

We suggest that future research might focus on a closer inspection of the AHCcomplex (a region affected by memantine activity) involvement in pharmacoresistant OCD. In this context, it is noteworthy that key structures of the TL memory system (i.e., hippocampal and parahippocampal regions) are interconnected predominantly by glutamatergic projection neurons [152]. Further neuroanatomical and electrophysiological evidence shows that projections connecting these regions with the amygdala are mainly mediated by glutamatergic pyramidal neurons (for a review see [153]). Based on the current knowledge it is mainly the ventral hippocampus that is responsible for anxiety and affects the amygdala (basolateral nucleus) response during the occurrence of a threatening stimulus (leading to avoidance behavior). The amygdala thus represents an anatomical structure that may substantially contribute to pharmacoresistancy related to the hyperactivity of the ventral hippocampus. Through this mechanism, the activation of avoidance behavior is facilitated, which itself poses a barrier to effective treatment of OCD.

\section{Acknowledgements}

We would like to thank two anonymous reviewers for their valuable comments which greatly helped improved the manuscript.

\section{Funding}

This work was supported by the grants AZV MHCR no. 15-34524A and 15-29370A, the project "NPU4NUDZ" no. LO1611, with a financial support from the MEYS under the NPU I program, by the Charles University research program PROGRES Q35, 260388/SVV/ 2017.

\section{Conflict of Interest}

No conflict of interest has been declared by the author(s).

\section{References}

[1] Bloch $\mathrm{MH}$, Pittenger $\mathrm{C}$. The genetics of obsessive-compulsive disorder. Curr Psychiatry Rev 2010; 6: 91-103

[2] Veale D, Roberts A. Obsessive-compulsive disorder. BM] 2014; 348 : g2183 
[3] Olesen J, Gustavsson A, Svensson M et al. The economic cost of brain disorders in Europe. Eur J Neurol 2012; 19: 155-162

[4] DuPont RL, Rice DP, Shiraki S et al. Economic costs of obsessive-compulsive disorder. Med Interface 1995; 8: 102-109

[5] Skapinakis P, Caldwell D, Hollingworth W et al. A systematic review of the clinical effectiveness and cost-effectiveness of pharmacological and psychological interventions for the management of obsessivecompulsive disorder in children/adolescents and adults. Health Technol Assess 2016; 20: 1-392

[6] Pittenger C, Bloch MH. Pharmacological treatment of obsessive-compulsive disorder. Psychiatr Clin North Am 2014; 37: 375-391

[7] Pallanti S, Hollander E, Bienstock $C$ et al. Treatment non-response in OCD: methodological issues and operational definitions. Int J Neuropsychopharmacol 2002; 5: 181-191

[8] Veale D, Miles S, Smallcombe $\mathrm{N}$ et al. Atypical antipsychotic augmentation in SSRI treatment refractory obsessive-compulsive disorder: A systematic review and meta-analysis. BMC Psychiatry 2014; 14: 317

[9] Denys D, de Geus F, van Megen HJ et al. A double-blind, randomized, placebo-controlled trial of quetiapine addition in patients with obsessive-compulsive disorder refractory to serotonin reuptake inhibitors. J Clin Psychiatry 2004; 65: 1040-1048

[10] Abudy A, Juven-Wetzler A, Zohar J. Pharmacological management of treatment-resistant obsessive-compulsive disorder. CNS Drugs 2011; 25: 585-596

[11] Karch S, Pogarell O. Neurobiology of obsessive-compulsive disorder. Nervenarzt 2011; 82: 299-307

[12] Abramovitch A, Mittelman A, Tankersley AP et al. Neuropsychological investigations in obsessive-compulsive disorder: A systematic review of methodological challenges. Psychiatry Res 2015; 228: 112-120

[13] Nakao T, Okada K, Kanba S. Neurobiological model of obsessive-compulsive disorder: evidence from recent neuropsychological and neuroimaging findings. Psychiatry Clin Neurosci 2014; 68: 587-605

[14] Clark CR, Galletly CA, Ash D] et al. Evidence-based medicine evaluation of electrophysiological studies of the anxiety disorders. Clin EEG Neurosci 2009; 40: 84-112

[15] Aouizerate B, Guehl D, Cuny E et al. Updated overview of the putative role of the serotoninergic system in obsessive-compulsive disorder. Neuropsychiatr Dis Treat 2005; 1: 231-243

[16] Goodman WK, Grice DE, Lapidus KA et al. Obsessive-compulsive disorder. Psychiatr Clin North Am 2014; 37: 257-267

[17] Prichep LS, Mas F, Hollander E et al. Quantitative electroencephalographic subtyping of obsessive-compulsive disorder. Psychiatry Res 1993; 50: 25-32

[18] Saxena S, Rauch SL. Functional neuroimaging and the neuroanatomy of obsessive-compulsive disorder. Psychiatr Clin North Am 2000; 23: 563-586

[19] Pauls DL, Abramovitch A, Rauch SL et al. Obsessive-compulsive disorder: An integrative genetic and neurobiological perspective. Nat Rev Neurosci 2014; 15: 410-424

[20] Singer HS, Morris C, Grados M. Glutamatergic modulatory therapy for Tourette syndrome. Med Hypotheses 2010; 74: 862-867

[21] Rosenberg DR, Keshavan MS. A.E. Bennett Research Award. Toward a neurodevelopmental model of obsessive-compulsive disorder. Biol Psychiatry 1998; 43: 623-640

[22] Grados MA, Specht MW, Sung HM et al. Glutamate drugs and pharmacogenetics of OCD: A pathway-based exploratory approach. Expert Opin Drug Discov 2013; 8: 1515-1527

[23] Garcia-Munoz M, Lopez-Huerta VG, Carrillo-Reid L et al. Extrasynaptic glutamate NMDA receptors: key players in striatal function. Neuropharmacology 2015; 89: 54-63

[24] Sampaio AS, Fagerness J, Crane J et al. Association between polymorphisms in GRIK2 gene and obsessive-compulsive disorder: A family-based study. CNS Neurosci Ther 2011; 17: 141-147
[25] Rotge JY, Aouizerate B, Tignol ] et al. The glutamate-based genetic immune hypothesis in obsessive-compulsive disorder. An integrative approach from genes to symptoms. Neuroscience 2010; 165: 408-417

[26] Arnold PD, Sicard T, Burroughs E et al. Glutamate transporter gene SLC1A1 associated with obsessive-compulsive disorder. Arch Gen Psychiatry 2006; 63: 769-776

[27] Mintzopoulos D, Gillis TE, Robertson HR et al. Striatal magnetic resonance spectroscopy abnormalities in young adult SAPAP3 knockout mice. Biol Psychiatry Cogn Neurosci Neuroimaging 2016; 1: 39-48

[28] Bozkurt A, Zilles K, Schleicher A et al. Distributions of transmitter receptors in the macaque cingulate cortex. Neuroimage 2005; 25 : 219-229

[29] Naaijen J, Lythgoe D], Amiri $\mathrm{H}$ et al. Fronto-striatal glutamatergic compounds in compulsive and impulsive syndromes: A review of magnetic resonance spectroscopy studies. Neurosci Biobehav Rev 2015; 52: 74-88

[30] Wu K, Hanna GL, Rosenberg DR et al. The role of glutamate signaling in the pathogenesis and treatment of obsessive-compulsive disorder. Pharmacol Biochem Behav 2012; 100: 726-735

[31] MacMaster FP. Translational neuroimaging research in pediatric obsessivecompulsive disorder. Dialogues Clin Neurosci 2010; 12: 165-174

[32] Rosenberg DR, MacMaster FP, Keshavan MS et al. Decrease in caudate glutamatergic concentrations in pediatric obsessive-compulsive disorder patients taking paroxetine. J Am Acad Child Adolesc Psychiatry 2000; 39: 1096-1103

[33] Rosenberg DR, Mirza Y, Russell A et al. Reduced anterior cingulate glutamatergic concentrations in childhood OCD and major depression versus healthy controls. J Am Acad Child Adolesc Psychiatry 2004; 43: 1146-1153

[34] Yucel M, Wood S], Wellard RM et al. Anterior cingulate glutamateglutamine levels predict symptom severity in women with obsessivecompulsive disorder. Aust N Z J Psychiatry 2008; 42: 467-477

[35] El Mansari M, Blier P. Mechanisms of action of current and potential pharmacotherapies of obsessive-compulsive disorder. Prog Neuropsychopharmacol Biol Psychiatry 2006; 30: 362-373

[36] Ortiz AE, Gasso P, Mas S et al. Association between genetic variants of serotonergic and glutamatergic pathways and the concentration of neurometabolites of the anterior cingulate cortex in paediatric patients with obsessive-compulsive disorder. World J Biol Psychiatry 2016; 17: 394-404

[37] Simpson HB, Kegeles LS, Hunter L et al. Assessment of glutamate in striatal subregions in obsessive-compulsive disorder with proton magnetic resonance spectroscopy. Psychiatry Res 2015; 232: 65-70

[38] Pujol J, Soriano-Mas C, Alonso P et al. Mapping structural brain alterations in obsessive-compulsive disorder. Arch Gen Psychiatry 2004; 61: 720-730

[39] Subira M, Alonso P, Segalas C et al. Brain structural alterations in obsessive-compulsive disorder patients with autogenous and reactive obsessions. PLoS One 2013; 8: e75273

[40] Rauch SL, Wedig MM, Wright $\mathrm{Cl}$ et al. Functional magnetic resonance imaging study of regional brain activation during implicit sequence learning in obsessive-compulsive disorder. Biol Psychiatry 2007; 61: 330-336

[41] Hendler T, Goshen E, Tadmor R et al. Evidence for striatal modulation in the presence of fixed cortical injury in obsessive-compulsive disorder (OCD). Eur Neuropsychopharmacol 1999; 9: 371-376

[42] den Braber A, van't Ent D, Cath D et al. A DTI study of monozygotic twins discordant for obsessive-compulsive symptoms. Neuroimage 2009; 47: S127

[43] Yoo S, Jang J, Shin YW et al. White matter abnormalities in drug-naïve patients with obsessive-compulsive disorder: A diffusion tensor Study before and after citalopram treatment. Acta Psychiatrica Scandinavica 2007; 116: 211-219 
[44] Yeterian EH, Pandya DN. Corticostriatal connections of the superior temporal region in rhesus monkeys. J Comp Neurol 1998; 399: 384-402

[45] Qian S, Sun G, Jiang Q et al. Altered topological patterns of large-scale brain functional networks during passive hyperthermia. Brain Cogn 2013; 83: 121-131

[46] Li F, Huang $X$, Yang $Y$ et al. Microstructural brain abnormalities in patients with obsessive-compulsive disorder: Diffusion-tensor MR imaging study at 3.0 T. Radiology 2011; 260: 216-223

[47] den Braber A, de Geus E], Boomsma DI et al. Obsessive-compulsive symptoms and related sex differences in brain structure: An MRI study in Dutch twins. Twin Res Hum Genet 2013; 16: 516-524

[48] Choi JS, Kim HS, Yoo SY et al. Morphometric alterations of anterior superior temporal cortex in obsessive-compulsive disorder. Depress Anxiety 2006; 23: 290-296

[49] Maihofner C, Sperling W, Kaltenhauser M et al. Spontaneous magnetoencephalographic activity in patients with obsessive-compulsive disorder. Brain Res 2007; 1129: 200-205

[50] Van Laere K, Nuttin B, Gabriels L et al. Metabolic imaging of anterior capsular stimulation in refractory obsessive-compulsive disorder: A key role for the subgenual anterior cingulate and ventral striatum. J Nucl Med 2006; 47: 740-747

[51] Zhang A, Leow A, Ajilore $O$ et al. Quantitative tract-specific measures of uncinate and cingulum in major depression using diffusion tensor imaging. Neuropsychopharmacology 2012; 37: 959-967

[52] Atmaca M. Review of structural neuroimaging in patients with refractory obsessive-compulsive disorder. Neurosci Bull 2011; 27: 215-220

[53] Inoue T, Kitaichi Y, Koyama T. SSRIs and conditioned fear. Prog Neuropsychopharmacol Biol Psychiatry 2011; 35: 1810-1819

[54] Reess T], Rus OG, Schmidt R et al. Connectomics-based structural network alterations in obsessive-compulsive disorder. Transl Psychiatry 2016; 6: e882

[55] Isaacs KL, Philbeck JW, Barr WB et al. Obsessive-compulsive symptoms in patients with temporal lobe epilepsy. Epilepsy Behav 2004; 5: 569-574

[56] Monaco F, Cavanna A, Magli E et al. Obsessionality, obsessive-compulsive disorder, and temporal lobe epilepsy. Epilepsy Behav 2005; 7 : 491-496

[57] Barbieri V, Lo Russo G, Francione S et al. Association of temporal lobe epilepsy and obsessive-compulsive disorder in a patient successfully treated with right temporal lobectomy. Epilepsy Behav 2005; 6: 617-619

[58] Kaplan PW. Epilepsy and obsessive-compulsive disorder. Dialogues Clin Neurosci 2010; 12: 241-248

[59] Hansen ES, Prichep LS, Bolwig TG et al. Quantitative electroencephalography in OCD patients treated with paroxetine. Clin Electroencephalogr 2003; 34: 70-74

[60] Locatelli M, Bellodi L, Grassi B et al. EEG power modifications in obsessive-compulsive disorder during olfactory stimulation. Biol Psychiatry 1996; 39: 326-331

[61] Rauch SL, Savage CR, Alpert NM et al. Probing striatal function in obsessive-compulsive disorder: A PET study of implicit sequence learning. J Neuropsychiatry Clin Neurosci 1997; 9: 568-573

[62] Rauch SL, Whalen PJ, Curran T et al. Probing striato-thalamic function in obsessive-compulsive disorder and Tourette syndrome using neuroimaging methods. Adv Neurol 2001; 85: 207-224

[63] Joel D, Zohar O, Afek $\mathrm{M}$ et al. Impaired procedural learning in obsessive-compulsive disorder and Parkinson's disease, but not in major depressive disorder. Behav Brain Res 2005; 157: 253-263

[64] Ullman MT, Pullman MY. A compensatory role for declarative memory in neurodevelopmental disorders. Neurosci Biobehav Rev 2015; 51: 205-222
[65] Peterson BS, Choi HA, Hao X et al. Morphologic features of the amygdala and hippocampus in children and adults with Tourette syndrome. Arch Gen Psychiatry 2007; 64: 1281-1291

[66] Rauch SL, Britton JC. Developmental neuroimaging studies of OCD: the maturation of a field. J Am Acad Child Adolesc Psychiatry 2010; 49: $1186-1188$

[67] DeCoteau WE, Kesner RP. A double dissociation between the rat hippocampus and medial caudoputamen in processing two forms of knowledge. Behav Neurosci 2000; 114: 1096-1108

[68] Rachman S. A cognitive theory of compulsive checking. Behav Res Ther 2002; 40: 625-639

[69] van den Hout M, Kindt M. Phenomenological validity of an OCD-memory model and the remember/know distinction. Behav Res Ther 2003; 41: 369-378

[70] van den Hout M, Kindt M. Repeated checking causes memory distrust. Behav Res Ther 2003; 41: 301-316

[71] van den Hout M, Kindt M. Obsessive-compulsive disorder and the paradoxical effects of perseverative behaviour on experienced uncertainty. J Behav Ther Exp Psychiatry 2004; 35: 165-181

[72] Tallis F, Pratt P, Jamani N. Obsessive compulsive disorder, checking, and non-verbal memory: A neuropsychological investigation. Behav Res Ther 1999; 37: 161-166

[73] Omori IM, Murata Y, Yamanishi T et al. The differential impact of executive attention dysfunction on episodic memory in obsessivecompulsive disorder patients with checking symptoms vs. those with washing symptoms. J Psychiatr Res 2007; 41: 776-784

[74] Kyrios M, Wainwright K, Purcell R et al. Neuropsychological performance in subtypes of obsessive-compulsive disorder. Paper presented at the 33rd conference of the Association for Advancement of Behavior Therapy 1999

[75] Mataix-Cols D, Junque C, Sanchez-Turet M et al. Neuropsychological functioning in a subclinical obsessive-compulsive sample. Biol Psychiatry 1999; 45: 898-904

[76] Nedeljkovic M, Kyrios M, Moulding R et al. Differences in neuropsychological performance between subtypes of obsessive-compulsive disorder. Aust N Z J Psychiatry 2009; 43: 216-226

[77] Ahmari SE, Eich T, Cebenoyan D et al. Assessing neurocognitive function in psychiatric disorders: A roadmap for enhancing consensus. Neurobiol Learn Mem 2014; 115: 10-20

[78] Radua J, Mataix-Cols D. Voxel-wise meta-analysis of grey matter changes in obsessive-compulsive disorder. Br J Psychiatry 2009; 195: 393-402

[79] van den Heuvel OA, Remijnse PL, Mataix-Cols D et al. The major symptom dimensions of obsessive-compulsive disorder are mediated by partially distinct neural systems. Brain 2009; 132: 853-868

[80] Via E, Cardoner N, Pujol J et al. Amygdala activation and symptom dimensions in obsessive-compulsive disorder. Br J Psychiatry 2014; 204: 61-68

[81] Alvarenga PG, do Rosário MC, Batistuzzo MC et al. Obsessive-compulsive symptom dimensions correlate to specific gray matter volumes in treatment-naïve patients. J Psychiatr Res 2012; 46: 1635-1642

[82] Valente AA Jr., Miguel EC, Castro CC et al. Regional gray matter abnormalities in obsessive-compulsive disorder: A voxel-based morphometry study. Biol Psychiatry 2005; 58: 479-487

[83] Lee HJ, Kwon SM, Kwon JS et al. Testing the autogenous-reactive model of obsessions. Depress Anxiety 2005; 21: 118-129

[84] Besiroglu L, Sozen M, Ozbebit O et al. The involvement of distinct neural systems in patients with obsessive-compulsive disorder with autogenous and reactive obsessions. Acta Psychiatr Scand 2011; 124 : 141-151

[85] Alonso P, Orbegozo A, Pujol J et al. Neural correlates of obsessivecompulsive related dysfunctional beliefs. Prog Neuropsychopharmacol Biol Psychiatry 2013; 47: 25-32 
[86] Pittenger C. Glutamate modulators in the treatment of obsessivecompulsive disorder. Psychiatr Ann 2015; 45: 308-315

[87] Kariuki-Nyuthe C, Gomez-Mancilla B, Stein DJ. Obsessive compulsive disorder and the glutamatergic system. Curr Opin Psychiatry 2014; 27: 32-37

[88] Pittenger C. Glutamatergic agents for $O C D$ and related disorders. Curr Treat Options Psychiatry 2015; 2: 271-283

[89] Kretschmer BD, Kratzer U, Schmidt W]. Riluzole, a glutamate release inhibitor, and motor behavior. Naunyn Schmiedebergs Arch Pharmacol 1998; 358: 181-190

[90] Pittenger C, Bloch MH, Wasylink S et al. Riluzole augmentation in treatment-refractory obsessive-compulsive disorder: A pilot randomized placebo-controlled trial. J Clin Psychiatry 2015; 76: 1075-1084

[91] Aida T, Yoshida J, Nomura M et al. Astroglial glutamate transporter deficiency increases synaptic excitability and leads to pathological repetitive behaviors in mice. Neuropsychopharmacology 2015; 40: 1569-1579

[92] Porton B, Greenberg BD, Askland K et al. Isoforms of the neuronal glutamate transporter gene, SLC1A1/EAAC1, negatively modulate glutamate uptake: relevance to obsessive-compulsive disorder. Transl Psychiatry 2013; 3: e259

[93] Veenstra-VanderWeele ], Xu T, Ruggiero AM et al. Functional studies and rare variant screening of SLC1A1/EAAC1 in males with obsessive-compulsive disorder. Psychiatr Genet 2012; 22: 256-260

[94] Gerhard DM, Wohleb ES, Duman RS. Emerging treatment mechanisms for depression: focus on glutamate and synaptic plasticity. Drug Discov Today 2016; 21: 454-464

[95] Kaster MP, Moretti M, Cunha MP et al. Novel approaches for the management of depressive disorders. Eur J Pharmacol 2016; 771: 236-240

[96] Rodriguez $\mathrm{Cl}$, Kegeles LS, Flood P et al. Rapid resolution of obsessions after an infusion of intravenous ketamine in a patient with treatment-resistant obsessive-compulsive disorder. J Clin Psychiatry 2011; 72: 567-569

[97] Rodriguez Cl, Kegeles LS, Levinson A et al. Randomized controlled crossover trial of ketamine in obsessive-compulsive disorder: proof-of-concept. Neuropsychopharmacology 2013; 38: 2475-2483

[98] Rodriguez $\mathrm{Cl}$, Levinson A, Zwerling J et al. Open-Label trial on the effects of memantine in adults with obsessive-compulsive disorder after a single ketamine infusion. J Clin Psychiatry 2016; 77: 688-689

[99] Bloch MH, Wasylink S, Landeros-Weisenberger A et al. Effects of ketamine in treatment-refractory obsessive-compulsive disorder. Biol Psychiatry 2012; 72: 964-970

[100] Hollander E, Dell'Osso B. Topiramate plus paroxetine in treatmentresistant obsessive-compulsive disorder. Int Clin Psychopharmacol 2006; 21: 189-191

[101] Berlin HA, Koran LM, Jenike MA et al. Double-blind, placebocontrolled trial of topiramate augmentation in treatment-resistant obsessive-compulsive disorder. J Clin Psychiatry 2011; 72: 716-721

[102] Hussain A, Dar MA, Wani RA et al. Role of lamotrigine augmentation in treatment-resistant obsessive compulsive disorder: A retrospective case review from South Asia. Indian J Psychol Med 2015; 37: 154-158

[103] Arrojo-Romero M, Tajes Alonso M, de Leon J. Lamotrigine augmentation of serotonin reuptake inhibitors in severe and long-term treatment-resistant obsessive-compulsive disorder. Case Rep Psychiatry 2013; 2013: 612459

[104] Uzun O. Lamotrigine as an augmentation agent in treatment-resistant obsessive-compulsive disorder: A case report. J Psychopharmacol 2010; 24: 425-427
[105] Bruno A, Mico U, Pandolfo G et al. Lamotrigine augmentation of serotonin reuptake inhibitors in treatment-resistant obsessive-compulsive disorder: A double-blind, placebo-controlled study. I Psychopharmacol 2012; 26: 1456-1462

[106] Sitges M, Chiu LM, Guarneros A et al. Effects of carbamazepine, phenytoin, lamotrigine, oxcarbazepine, topiramate and vinpocetine on $\mathrm{Na}+$ channel-mediated release of [3H]glutamate in hippocampal nerve endings. Neuropharmacology 2007; 52: 598-605

[107] Waldmeier PC, Martin P, Stocklin K et al. Effect of carbamazepine, oxcarbazepine and lamotrigine on the increase in extracellular glutamate elicited by veratridine in rat cortex and striatum. Naunyn Schmiedebergs Arch Pharmacol 1996; 354: 164-172

[108] Wang S], Sihra TS, Gean PW. Lamotrigine inhibition of glutamate release from isolated cerebrocortical nerve terminals (synaptosomes) by suppression of voltage-activated calcium channel activity. Neuroreport 2001; 12: 2255-2258

[109] Cunningham MO, Jones RS. The anticonvulsant, lamotrigine decreases spontaneous glutamate release but increases spontaneous GABA release in the rat entorhinal cortex in vitro. Neuropharmacology 2000; 39: 2139-2146

[110] Brennan BP, Jensen JE, Perriello C et al. Lower posterior cingulate cortex glutathione levels in obsessive-compulsive disorder. Biol Psychiatry Cogn Neurosci Neuroimaging 2016; 1: 116-124

[111] Simsek S, Gencoglan S, Yuksel T. DNA damage and antioxidants in treatment naive children with obsessive-compulsive disorder. Psychiatry Res 2016; 237: 133-137

[112] Dean O, Giorlando F, Berk M. N-acetylcysteine in psychiatry: current therapeutic evidence and potential mechanisms of action. J Psychiatry Neurosci 2011; 36: 78-86

[113] Oliver G, Dean O, Camfield D et al. N-acetyl cysteine in the treatment of obsessive compulsive and related disorders: A systematic review. Clin Psychopharmacol Neurosci 2015; 13: 12-24

[114] Corbit LH, Chieng BC, Balleine BW. Effects of repeated cocaine exposure on habit learning and reversal by $\mathrm{N}$-acetylcysteine. Neuropsychopharmacology 2014; 39: 1893-1901

[115] Kupchik YM, Moussawi K, Tang XC et al. The effect of $\mathrm{N}$-acetylcysteine in the nucleus accumbens on neurotransmission and relapse to cocaine. Biol Psychiatry 2012; 71: 978-986

[116] Minarini A, Ferrari S, Galletti M et al. $\mathrm{N}$-acetylcysteine in the treatment of psychiatric disorders: Current status and future prospects. Expert Opin Drug Metab Toxicol 2017; 13: 279-292

[117] Norberg MM, Krystal JH, Tolin DF. A meta-analysis of D-cycloserine and the facilitation of fear extinction and exposure therapy. Biol Psychiatry 2008; 63: 1118-1126

[118] Hofmann SG, Otto MW, Pollack MH et al. D-cycloserine augmentation of cognitive behavioral therapy for anxiety disorders: An update. Curr Psychiatry Rep 2015; 17: 532

[119] Goff DC. D-cycloserine in schizophrenia: New strategies for improving clinical outcomes by enhancing plasticity. Curr Neuropharmacol 2017; 15: 21-34

[120] Storch EA, Wilhelm S, Sprich S et al. Efficacy of augmentation of cognitive behavior therapy with weight-adjusted d-cycloserine vs placebo in pediatric obsessive-compulsive disorder: A randomized clinical trial. JAMA Psychiatry 2016; 73: 779-788

[121] Wilhelm S, Buhlmann U, Tolin DF et al. Augmentation of behavior therapy with D-cycloserine for obsessive-compulsive disorder. Am J Psychiatry 2008; 165: 335-341

[122] Chasson GS, Buhlmann U, Tolin DF et al. Need for speed: evaluating slopes of OCD recovery in behavior therapy enhanced with d-cycloserine. Behav Res Ther 2010; 48: 675-679

[123] Kushner MG, Kim SW, Donahue C et al. D-cycloserine augmented exposure therapy for obsessive-compulsive disorder. Biol Psychiatry 2007; 62: 835-838 
[124] Andersson E, Hedman E, Enander J et al. D-cycloserine vs placebo as adjunct to cognitive behavioral therapy for obsessive-compulsive disorder and interaction with antidepressants: A randomized clinical trial. JAMA Psychiatry 2015; 72: 659-667

[125] de Leeuw AS, van Megen H], Kahn RS et al. D-cycloserine addition to exposure sessions in the treatment of patients with obsessive-compulsive disorder. Eur Psychiatry 2017; 40: 38-44

[126] Greenberg WM, Benedict MM, Doerfer J et al. Adjunctive glycine in the treatment of obsessive-compulsive disorder in adults. J Psychiatr Res 2009; 43: 664-670

[127] Bugarski-Kirola D, Wang A, Abi-Saab D et al. A phase II/III trial of bitopertin monotherapy compared with placebo in patients with an acute exacerbation of schizophrenia-results from the CandleLyte study. European Neuropsychopharmacology 2014; 24: 1024-1036

[128] Rodriguez Cl, Zwerling J, Kalanthroff E et al. Effect of a novel NMDA receptor modulator, rapastinel (formerly GLYX-13), in OCD: Proof of concept. Am J Psychiatry 2016; 173: 1239-1241

[129] Javelot H. Psychopharmacology of anxiety and depression: Historical aspects, current treatments and perspectives. Ann Pharm Fr 2016; 74: $93-118$

[130] Hezel DM, Beattie K, Stewart SE. Memantine as an augmenting agent for severe pediatric OCD. Am J Psychiatry 2009; 166: 237

[131] Stewart SE, Jenike EA, Hezel DM et al. A single-blinded case-control study of memantine in severe obsessive-compulsive disorder. J Clin Psychopharmacol 2010; 30: 34-39

[132] Haghighi M, Jahangard L, Mohammad-Beigi $\mathrm{H}$ et al. In a double-blind, randomized and placebo-controlled trial, adjuvant memantine improved symptoms in inpatients suffering from refractory obsessive-compulsive disorders (OCD). Psychopharmacology (Berl) 2013; 228: 633-640

[133] Ghaleiha A, Entezari N, Modabbernia A et al. Memantine add-on in moderate to severe obsessive-compulsive disorder: Randomized double-blind placebo-controlled study. J Psychiatr Res 2013; 47: $175-180$

[134] Saxena S, Bota RG, Brody AL. Brain-behavior relationships in obsessive-compulsive disorder. Semin Clin Neuropsychiatry 2001; 6 : 82-101

[135] Schipke CG, Heuser I, Peters O. Antidepressants act on glial cells: SSRIs and serotonin elicit astrocyte calcium signaling in the mouse prefrontal cortex. J Psychiatr Res 2011; 45: 242-248

[136] Golembiowska K, Dziubina A. Effect of acute and chronic administration of citalopram on glutamate and aspartate release in the rat prefrontal cortex. Pol J Pharmacol 2000; 52: 441-448

[137] McEwen BS, Chattarji S. Molecular mechanisms of neuroplasticity and pharmacological implications: The example of tianeptine. Eur Neuropsychopharmacol 2004; 14: (Suppl 5): S497-S502

[138] Sekar S, Jonckers E, Verhoye M et al. Subchronic memantine induced concurrent functional disconnectivity and altered ultra-structural tissue integrity in the rodent brain: Revealed by multimodal MRI. Psychopharmacology (Berl) 2013; 227: 479-491

[139] Kim YW, Shin JC, An YS. Changes in cerebral glucose metabolism in patients with posttraumatic cognitive impairment after memantine therapy: A preliminary study. Ann Nucl Med 2010; 24: 363-369

[140] Mares P, Mikulecka A. Different effects of two N-methyl-D-aspartate receptor antagonists on seizures, spontaneous behavior, and motor performance in immature rats. Epilepsy Behav 2009; 14: 32-39

[141] Kohl BK, Dannhardt G. The NMDA receptor complex: A promising target for novel antiepileptic strategies. Curr Med Chem. 2001; 8: 1275-1289

[142] Jia LJ, Wang WP, Li ZP et al. Memantine attenuates the impairment of spatial learning and memory of pentylenetetrazol-kindled rats. Neurol Sci 2011; 32: 609-613
[143] Marimuthu P, Varadarajan S, Krishnan M et al. Evaluating the efficacy of memantine on improving cognitive functions in epileptic patients receiving anti-epileptic drugs: A double-blind placebo-controlled clinical trial (Phase IIIb pilot study). Ann Indian Acad Neurol 2016; 19 : 344-350

[144] Zaitsev AV, Kim K, Vasilev DS et al. N-methyl-D-aspartate receptor channel blockers prevent pentylenetetrazole-induced convulsions and morphological changes in rat brain neurons. J Neurosci Res 2015; 93: 454-465

[145] Reniers RL, Vollm BA, Elliott R et al. Empathy, ToM, and self-other differentiation: An fMRI study of internal states. Soc Neurosci 2014; 9: 50-62

[146] Busigny T, Robaye L, Dricot L et al. Right anterior temporal lobe atrophy and person-based semantic defect: A detailed case study. Neurocase 2009; 15: 485-508

[147] Helmstaedter C, Richter S, Röske S et al. Differential effects of temporal pole resection with amygdalohippocampectomy versus selective amygdalohippocampectomy on material-specific memory in patients with mesial temporal lobe epilepsy. Epilepsia 2008; 49: 88-97

[148] Skirrow C, Cross JH, Harrison S et al. Temporal lobe surgery in childhood and neuroanatomical predictors of long-term declarative memory outcome. Brain 2015; 138: 80-93

[149] Olson IR, Plotzker A, Ezzyat Y. The enigmatic temporal pole: A review of findings on social and emotional processing. Brain 2007; 130: 1718-1731

[150] Pasquini M, Biondi M. Memantine augmentation for refractory obsessive-compulsive disorder. Prog Neuropsychopharmacol Biol Psychiatry 2006; 30: 1173-1175

[151] Poyurovsky M, Weizman R, Weizman A et al. Memantine for treatment-resistant OCD. Am J Psychiatry 2005; 162: 2191-2192

[152] Amaral D, Witter M, Paxinos G. The Rat Nervous System. San Diego: Academic Press; 1995: 443-485

[153] McDonald AJ, Mott DD. Functional neuroanatomy of amygdalohippocampal interconnections and their role in learning and memory. J Neurosci Res 2017; 95: 797-820

[154] Storch EA, Merlo LJ, Bengtson M et al. D-cycloserine does not enhance exposure-response prevention therapy in obsessivecompulsive disorder. Int Clin Psychopharmacol 2007; 22: 230-237

[155] Storch EA, Murphy TK, Goodman WK et al. A preliminary study of $\mathrm{D}$-cycloserine augmentation of cognitive-behavioral therapy in pediatric obsessive-compulsive disorder. Biol Psychiatry 2010; 68: 1073-1076

[156] Park JM, Small BJ, Geller DA et al. Does d-cycloserine augmentation of CBT improve therapeutic homework compliance for pediatric obsessive-compulsive disorder? J Child Fam Stud 2014; 23 : 863-871

[157] Olatunji BO, Rosenfield D, Monzani B et al. Effects of homework compliance on cognitive-behavioral therapy with d-cycloserine augmentation for children with obsessive compulsive disorder. Depress Anxiety 2015; 32: 935-943

[158] Afshar H, Roohafza H, Mohammad-Beigi $\mathrm{H}$ et al. N-acetylcysteine add-on treatment in refractory obsessive-compulsive disorder: A randomized, double-blind, placebo-controlled trial. J Clin Psychopharmacol 2012; 32: 797-803

[159] Sarris J, Oliver G, Camfield DA et al. N-acetyl cysteine (NAC) in the treatment of obsessive-compulsive disorder: A 16-week, doubleblind, randomised, placebo-controlled study. CNS Drugs 2015; 29: 801-809

[160] Paydary K, Akamaloo A, Ahmadipour A et al. N-acetylcysteine augmentation therapy for moderate-to-severe obsessive-compulsive disorder: Randomized, double-blind, placebo-controlled trial. J Clin Pharm Ther 2016; 41: 214-219 
[161] Costa DLC, Diniz JB, Requena G et al. Randomized, double-blind, placebo-controlled trial of $\mathrm{N}$-acetylcysteine augmentation for treatment-resistant obsessive-compulsive disorder. J Clin Psychiatry 2017 [Epub ahead of print]

[162] Ghanizadeh A, Mohammadi MR. Bahraini S, et al. Efficacy of $\mathrm{N}$-acetylcysteine augmentation on obsessive compulsive disorder: A multicenter randomized double blind placebo controlled clinical trial. Iran J Psychiatry 2017; 12: 134-141

[163] Grant PJ, Joseph LA, Farmer CA et al. 12-week, placebo-controlled trial of add-on riluzole in the treatment of childhood-onset obsessivecompulsive disorder. Neuropsychopharmacology 2014; 39 :

1453-1459
[164] Mowla A, Khajeian AM, Sahraian A et al. Topiramate augmentation in resistant OCD: A double-blind placebo-controlled clinical trial. CNS Spectr 2010; 15: 613-617

[165] Afshar H, Akuchekian S, Mahaky B et al. Topiramate augmentation in refractory obsessive-compulsive disorder: A randomized, doubleblind, placebo-controlled trial. J Res Med Sci 2014; 19: 976-981 